\title{
Inadequate Prescription-Drug Coverage for Medicare Enrollees - A Call to Action
}

\section{Citation}

Soumerai, Stephen B., and Dennis Ross-Degnan. 1999. "Inadequate Prescription-Drug Coverage for Medicare Enrollees - A Call to Action." New England Journal of Medicine 340 (9) (March 4): 722-728. doi:10.1056/nejm199903043400909.

\section{Published Version}

doi:10.1056/NEJM199903043400909

\section{Permanent link}

http://nrs.harvard.edu/urn-3:HUL.InstRepos:32692590

\section{Terms of Use}

This article was downloaded from Harvard University's DASH repository, and is made available under the terms and conditions applicable to Other Posted Material, as set forth at http:// nrs.harvard.edu/urn-3:HUL.InstRepos:dash.current.terms-of-use\#LAA

\section{Share Your Story}

The Harvard community has made this article openly available.

Please share how this access benefits you. Submit a story.

\section{Accessibility}


Sounding Board

\section{Inadequate Prescription-Drug Coverage For MEdicare Enrollees - A Call to Action}

$\mathrm{T}$ HE demise of both the Medicare Catastrophic Coverage Act of $1988^{1}$ and the 1993 Clinton plan for health care reform ${ }^{2,3}$ resulted in missed opportunities to correct a glaring defect in the American health care system - inadequate coverage for costly prescription drugs among low-income elderly and disabled persons. Although sometimes misused, prescription drugs are effective treatments for many illnesses. ${ }^{4,5}$ Most Medicare enrollees do not have adequate coverage for outpatient drug expenditures, since Medicare covers only drugs prescribed for inpatient use. Lack of coverage for outpatient drug expenditures is a formidable barrier to effective therapy. In this article, we describe the problem of inadequate coverage for outpatient drug expenditures among elderly and disabled persons in the United States, recent trends that have exacerbated the problem, and the economic and clinical consequences of the underuse of medications. We then propose a potential solution to this problem.

\section{THE PROBLEM}

Medicare enrollees include the elderly, the disabled, and patients with end-stage renal disease. The high prevalence of chronic illnesses among Medicare enrollees results in a disproportionate need for drugs prescribed for use on an outpatient basis. Although elderly persons represent only 12.4 percent of the U.S. population, ${ }^{6}$ they account for about a third of drug expenditures. ${ }^{7,8}$ About 85 percent of Medicare patients receive at least one prescription each year. ${ }^{7}$ In 1992, the average annual expenditure for prescription drugs was $\$ 549$ per recipient (among noninstitutionalized enrollees), over half of which was paid out of pocket. ${ }^{79}$ However, individual rates of use vary dramatically. For example, at Harvard Pilgrim Health Care, a health maintenance organization (HMO) in Massachusetts that in one plan provided unlimited prescription-drug coverage for 21,382 Medicare enrollees, the average outpatient drug expenditure per Medicare enrollee was \$1,153 in 1998 (Winkels M: personal communication). However, for the 10 percent of enrollees with the highest level of drug use, the average expenditure was $\$ 3,953$, and total outpatient drug expenditures for this group represented a third of those for all Medicare enrollees in this plan.

\section{Poverty and Lack of Coverage}

The incomes of many elderly and disabled citizens are too low for them to meet their basic needs and purchase "optional" medical care. In 1995, about 10 percent of the $\mathbf{3 7 . 7}$ million elderly persons enrolled in Medicare were classified as poor (defined as having an annual income below the federal poverty threshold of $\$ 7,309$ for a single person and $\$ 9,212$ for a couple); another 7 percent were "near-poor" (they had an annual income of less than $\$ 9,316$ and $\$ 14,618$, respectively). ${ }^{10}$

In 1997, 56 percent of Medicare beneficiaries had some prescription-drug coverage through private employers, private insurance to supplement Medicare, Medicaid, or Medicare HMOs. The rest had no coverage for outpatient drug expenditures. ${ }^{11}$ Almost 60 percent of Medicare enrollees with incomes below the federal poverty threshold were not enrolled in Medicaid in 1997.12 Even for Medicare enrollees with prescription-drug coverage, restricted benefits or high copayments can substantially reduce access. ${ }^{13}$ For example, in 1997, 11 state Medicaid programs imposed caps on the monthly number of prescriptions covered. ${ }^{14}$ Although most Medicare HMOs offer drug coverage, 87 percent impose annual caps, some of which are as low as $\$ 600 .{ }^{15}$ The high cost of supplemental insurance policies that cover medications (up to $\$ 3,200$ per year), ${ }^{16}$ makes them too expensive for most low-income Medicare enrollees.

Among Medicare enrollees, the 64 percent with no coverage for outpatient drug costs ${ }^{17}$ tend to be sicker and poorer than their counterparts with supplemental insurance. Forty percent of Medicare enrollees without prescription-drug coverage report that their health is only fair or poor, as compared with 23 percent of enrollees who have some coverage. ${ }^{7}$ In 1992 , one third of Medicare enrollees with no additional insurance had incomes of less than $\$ 7,500$ per person, as compared with 16 percent of those with private supplemental insurance, 8 percent of those with employer-sponsored insurance, and 12 percent of those in Medicare HMOs. ${ }^{7}$

\section{Rising Costs and Poorer Access}

Drug expenditures in the United States increased by 12.6 percent annually between 1994 and 1997 . This represents a more rapid average rate of growth than that of any other category of health services and is almost four times the rate of growth of hospital expenditures (3.4 percent per year). ${ }^{8}$ Outpatient drug expenditures for all Harvard Pilgrim Health Care members - not just Medicare enrollees rose from 7 percent of total medical expenditures in 1994 to over 13 percent in 1998, and if unchecked, they are projected to overtake hospital expenditures (about 20 percent of costs) by the year 2002 (Dorsey $\mathrm{J}$ : personal communication). Much of this increase 
reflects an increased use of drugs, particularly those that are new and effective but costly. ${ }^{8,18}$ Medicare patients facing higher out-of-pocket costs frequently stretch existing medication supplies or refrain from filling expensive prescriptions. ${ }^{13,19,20}$

In contrast to the explosive increases in expenditures for drugs, benefits from Social Security and Supplemental Security Income increased by only 1.3 percent in 1999.21 Already, poor elderly persons without Medicaid coverage spend approximately 50 percent of their total income (the near-poor spend 30 percent) on out-of-pocket health care costs, such as Medicare premiums and prescription drugs. ${ }^{12}$ There are anecdotal reports of low-income elderly persons who have stopped using essential drugs in order to pay for food..$^{20,22}$

Private competition has become the de facto organizational model for the U.S. health care system. In such a milieu, organizational survival demands a large number of patients and an ability to control costs. Many Medicare HMOs introduced coverage for outpatient drug costs in part to encourage patients to switch from fee-for-service Medicare. Plans offering unlimited coverage for outpatient drug costs have tended to attract the sickest patients and have had the largest increases in Medicare expenditures. These issues have been particularly problematic in Massachusetts, where, until recently, a state law required all Medicare HMOs providing drug benefits to offer an unlimited drug-coverage plan. ${ }^{23}$ After a federal court overturned this requirement, most plans discontinued unlimited coverage and placed caps on Medicare drug coverage, ranging from $\$ 150$ to $\$ 200$ per quarter. ${ }^{23}$ These caps have the greatest impact on the sickest and poorest patients. They may also increase rather than decrease overall costs because of unintended increases in hospital and nursing home admissions. ${ }^{5,13}$ In Massachusetts, some HMOs have transitional programs that provide unlimited drug coverage for Medicare enrollees with low incomes, but this assistance is likely to end next year.

\section{Adverse Consequences}

With inadequate or nonexistent drug coverage, the overall use of drugs is reduced, including the use of clinically important medications. Although Medicare enrollees with fair or poor health spend two to three times as much on drugs as those in excellent health, regardless of the type of insurance plan, enrollees without private insurance or Medicaid coverage have strikingly lower drug expenditures than those with individual or employer-sponsored private insurance (Fig. 1). ${ }^{7}$ Moreover, since some insurance plans that supplement Medicare provide inadequate or no drug coverage, and since the uninsured are likely to spend more per prescription than members of large insurance plans, the true difference in the

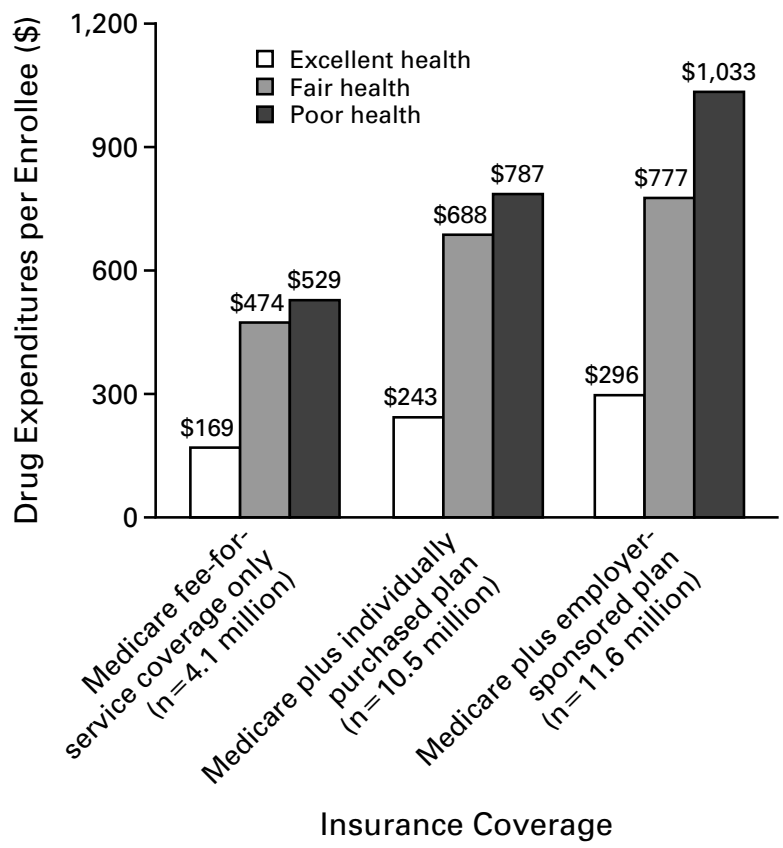

Figure 1. Average Drug Expenditures in 1992 among Noninstitutionalized Medicare Enrollees, According to Health and Insurance Status.

Data are from the 1992 Medicare Beneficiary Survey, with a total sample of 13,000 Medicare enrollees. ${ }^{7}$ Medicaid enrollees and HMO members are not included.

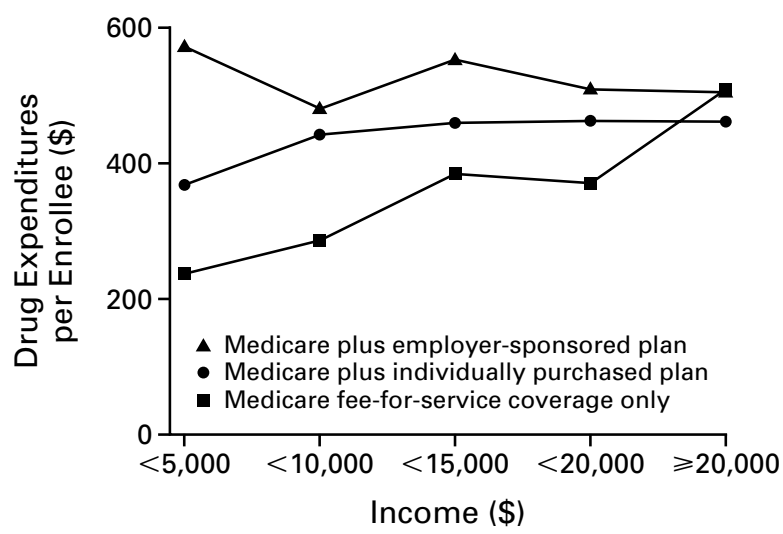

Figure 2. Average Drug Expenditures in 1992 among Noninstitutionalized Medicare Enrollees, According to Income and Insurance Status.

Data are from the 1992 Medicare Beneficiary Survey, with a total sample of 13,000 Medicare enrollees. ${ }^{7}$ Medicaid enrollees and HMO members are not included.

use of prescription drugs between those with adequate coverage and those without adequate coverage is probably even greater.

Additional evidence of the negative effects of low income on use of prescription drugs is shown in Figure 2. Medicare patients with the lowest annual 
incomes $(<\$ 5,000)$ and without drug coverage (excluding Medicaid enrollees) spend less than half as much on drugs as those with employer-sponsored insurance and two thirds as much as those with individual policies. Drug use rises steadily with income for the Medicare-only group; in the highest income category $(\geqslant \$ 20,000)$, there is little or no difference in drug use according to the type of coverage. Again, these disparities would be even greater if it were possible to control for the higher prevalence of poor health among persons without drug coverage.

Disparities in the use of medications according to income and type of coverage would be of less concern if the differences were confined to inappropriate or nonessential drugs. However, a large controlled study of the effects of a 1981 change in the New Hampshire Medicaid program from unlimited drug coverage to a limit of three prescriptions per month found that, among elderly and disabled persons with a high base-line use of medications, there were significant declines in the use of essential medications (e.g., insulin, lithium, cardiovascular agents, and bronchodilators) ${ }^{24}$ Among patients with schizophrenia, the change also resulted in reduced use of antipsychotic and antidepressant agents that prevent relapse. ${ }^{5}$ In 1991, a less severe reduction in coverage in the Georgia Medicaid program (from six prescriptions to five per month) had similar results..$^{25}$

Restricted coverage for needed drugs may be a false economy. A follow-up study in New Hampshire found that chronically ill elderly persons affected by limits on Medicaid drug payments were twice as likely as members of a control cohort to enter nursing homes, where they remained permanently in most cases. ${ }^{26}$ Increased nursing home and hospital stays during the 11 months the cap was in effect cost Medicaid more than the program saved in drug expenditures. Similarly, reduced use of psychotropic drugs among patients with schizophrenia doubled the use of emergency and day-hospital services. Increases in state costs for mental health care surpassed Medicaid drug savings by a factor of $17 .^{5}$ It is likely that many elderly persons without drug coverage also have avoidable episodes of illness, which lead to increased use of expensive institutional services paid for by state and federal governments.

Although unlimited access to all new, high-cost medications is certainly not justifiable, many new medications can reduce the need for expensive services. For example, a large clinical trial showed that the use of clozapine led to greater reductions in symptoms than haloperidol in patients with treatmentresistant schizophrenia and that the lower hospitalization costs in the group of patients who received clozapine more than offset the higher cost of the drug. ${ }^{27}$ Similar results have been reported for other drugs. ${ }^{28-32}$

\section{CURRENT PROPOSALS}

The problem of inadequate drug coverage for the elderly and disabled will soon become a crisis; there were 38.6 million Medicare beneficiaries in 1997, and the number is projected to reach 56.3 million by $2017 .^{33}$ Ensuring access to clinically important medications for elderly citizens is a social obligation. Even those who reject such a social contract should recognize that the lack of access to essential medicines for the growing number of chronically ill persons is likely to result in increased hospital and nursing home costs. ${ }^{5,26}$ Currently, 14 states provide some drug benefits for poor elderly and disabled persons who do not qualify for Medicaid (Table 1). However, eligibility for these commendable programs and their scope of coverage vary widely. Copayments range from $\$ 3$ per prescription to 40 percent of drug costs. The states with the largest programs, Pennsylvania (with two related programs) and New Jersey, enrolled over 200,000 persons each in 1996, at a total cost of \$222 million and \$198 million, respectively. However, the majority of low-income Medicare enrollees do not live in states with such programs.

The National Bipartisan Commission on the $\mathrm{Fu}^{-}$ ture of Medicare is considering whether to recommend creating drug coverage for Medicare enrollees. ${ }^{20}$ In addition, it is likely that members of Congress will present proposals to enact universal drug coverage as a Medicare Part B benefit. Such proposals may include partial financing with funds obtained by charging tobacco companies for the costs incurred by Medicare for the treatment of smoking-related diseases, require no additional premiums for those with existing coverage, and offer lower premiums and deductibles for low-income enrollees. These proposals have many strengths, such as defining drug coverage as part of the Medicare social contract, modernizing Medicare to achieve parity with comprehensive commercial insurance programs, avoiding means testing, and obtaining economies of scale in order to negotiate volume discounts on drug prices. However, it may be difficult to obtain widespread congressional support for these proposals. One reason is the estimated annual price tag of about $\$ 20$ billion. ${ }^{35}$ Another is the implicit trade-off between using additional federal health care dollars to provide other important benefits and using the funds to pay for Medicare coverage of prescription drugs. From an equity perspective, some would see a universal drug benefit for Medicare beneficiaries as an unjustifiable transfer of income to persons already able to pay for private insurance. Expanding health insurance to cover uninsured persons under the age of 65 years might be viewed as a better use of additional federal health care dollars. Efforts to make the legislation less costly might result in high deductibles (e.g., \$500) and prescription copayments (20 percent or more of drug costs). ${ }^{35}$ These measures would impose substantial 
Table 1. Characteristics of State Pharmacy-Assistance Programs for Elderly and Disabled Persons.*

\begin{tabular}{|c|c|c|c|c|c|c|c|c|}
\hline Characteristic & NeW Jersey & MARYLAND & Pennsylvania & Pennsylvaniat & ILLINOIS & RHODE ISLAND & Connecticut & New York \\
\hline Year enacted & 1977 & 1979 & 1984 & 1986 & 1985 & 1985 & 1986 & 1987 \\
\hline \multicolumn{9}{|l|}{$\begin{array}{l}\text { Eligibility criteria } \\
\text { Age (vr) }\end{array}$} \\
\hline Elderly & $\geqslant 65$ & All ages & $\geqslant 65$ & $\geqslant 65$ & $\geqslant 65$ & $\geqslant 65$ & $\geqslant 65$ & $\geqslant 65$ \\
\hline Disabled $\ddagger$ & $\geqslant 21$ & All ages & NA & NA & $\geqslant 16$ & $\geqslant 65$ & $\geqslant 18$ & NA \\
\hline \multicolumn{9}{|l|}{ Income $(\$)^{\top}$} \\
\hline Single & $\leqslant 17,550$ & $\leqslant 9,520$ & $\leqslant 14,000$ & $\leqslant 16,000$ & $\leqslant 7,890$ & $\leqslant 15,358$ & $\leqslant 14,200$ & $\leqslant 18,500$ \\
\hline Married & $\leqslant 21,519$ & $\leqslant 10,050$ & $\leqslant 17,200$ & $\leqslant 19,200$ & $\leqslant 10,610$ & $\leqslant 19,199$ & $\leqslant 17,200$ & $\leqslant 24,000$ \\
\hline Manufacturer’s discount $\$$ & Medicaid & Medicaid & Other & Other & Other & Medicaid & Medicaid & Medicaid \\
\hline Deductible (\$) & None & None & None & 500 & 15 & None & None & None \\
\hline Copayment & $\$ 5$ & $\$ 5$ & $\$ 6$ & $\begin{array}{l}\$ 8 \text { for generic } \\
\text { drug, } \$ 15 \\
\text { for brand- } \\
\text { name drug }\end{array}$ & $\begin{array}{c}20 \% \text { of cost after } \\
\$ 800 \text { benefit }\end{array}$ & $40 \%$ of cost & $\$ 12$ & $\begin{array}{l}\$ 3 \text { to } \$ 23 \text { ac- } \\
\text { cording to } \\
\text { drug cost }\end{array}$ \\
\hline Prescription drugs covered & All drugs & $\begin{array}{l}\text { Drugs for spec- } \\
\text { ified chronic } \\
\text { conditions }\end{array}$ & Most drugs & Most drugs & $\begin{array}{l}\text { Drugs for car- } \\
\text { diovascular } \\
\text { diseases, dia- } \\
\text { betes, arthritis }\end{array}$ & $\begin{array}{l}\text { Drugs for spec- } \\
\text { ified chronic } \\
\text { illnesses }\end{array}$ & Most drugs & Most drugs \\
\hline Source of funding $\mathbb{I}$ & $\begin{array}{l}\text { General fund, } \\
\text { casino }\end{array}$ & General fund & Lottery & Lottery & General fund & State revenue & State budget & General fund \\
\hline Enrollment (no.)\| & 205,900 & 34,000 & 260,000 & 12,889 & 60,847 & 27,000 & 37,676 & 94,800 \\
\hline Cost per participant $(\$) \mathbb{I}$ & 963.09 & 474.36 & 855.35 & NA & 531.57 & 410.8 & 700.33 & 582.00 \\
\hline $\begin{array}{l}\text { Program cost per year } \\
\text { (millions of } \$)\end{array}$ & 198.30 & 16.13 & 222.39 & NA & 32.34 & 11.09 & 26.39 & 55.17 \\
\hline
\end{tabular}

*Data are from the National Pharmaceutical Counci ${ }^{34}$ and the American Association of Retired Persons (AARP) Public Policy Institute. State programs with fewer than 25,000 participants (programs in Delaware, Maine, Massachusetts, Michigan, Minnesota, Vermont, and Wyoming) are not included. NA denotes not available.

†This second pharmacy-assistance program in Pennsylvania covers persons with slightly higher incomes than the other program and has higher copayments and deductibles.

‡Eligibility criteria for New Jersey and Illinois are based on data from the AARP for fiscal year 1998; eligibility criteria for Maryland, Rhode Island, and Connecticut are based on National Pharmaceutical Council data for fiscal year 1996.

SInformation on drug discounts is based on data from the National Pharmaceutical Council for fiscal year 1996. "Medicaid" denotes rebates that are similar to those received by Medicaid. "Other" denotes other program-based discounts based on the best prices given to other purchasers.

IInformation is based on data from the National Pharmaceutical Council for fiscal year 1996.

\|Enrollment figures for Maryland and Illinois are based on data from the National Pharmaceutical Council for fiscal year 1996; enrollment figures for the other states are based on AARP data for fiscal year 1998.

barriers to access for low-income enrollees. Furthermore, the enactment of such a large federal entitlement program, even if it is passed, might take years, while vulnerable low-income enrollees continue to have to choose between food and medicine.

Other proposed remedies involve the regulation of pharmaceutical prices. Congressman Tom Allen (D-Me.) has proposed legislation to give Medicare enrollees the same discount on drug prices (about 40 percent) that is currently provided by pharmaceutical companies to federal health insurance programs. ${ }^{36}$ This proposal is attractive, given the inordinately high prescription prices paid by persons who are not covered by large insurance plans with the leverage to negotiate reduced prices. However, price controls on drugs in the absence of expanded coverage may have unintended consequences.

First, drug companies are likely to offset sudden losses of income from Medicare prescriptions by raising the prices of drugs purchased by other govern- ment programs and in the private sector. ${ }^{37}$ In fact, this is exactly what happened after the enactment of federal legislation in 1990 that required drug manufacturers to give state Medicaid programs rebates for the costs of outpatient drugs equal to 15 percent of the average manufacturer's price or the difference between the average manufacturer's price and the lowest price charged to other purchasers. ${ }^{38}$ Many pharmaceutical companies attempted to minimize the financial effects of this requirement by simply raising drug prices for other purchasers in the private sector. In contrast to such price controls, programs to expand drug coverage might lower prices without the need for price regulation, by allowing negotiated volume discounts. ${ }^{13}$

Second, the pharmaceutical industry has launched a "lobbying blitz" to stop the proposed bill, ${ }^{36}$ charging that it will reduce investments in research and development and delay the discovery of effective medications for the elderly - contentions that are impossible to refute or prove. Finally, such approaches 
do not directly address the serious problem of the lack of drug coverage among the poor and near-poor, for whom lower prices are simply not enough.

\section{A FEASIBLE SOLUTION}

A federal-state program to cover poor, near-poor, and low-income Medicare beneficiaries who are ineligible for Medicaid is a cost-effective and politically feasible policy alternative. Such an incremental approach would target the elderly and disabled persons with the greatest economic and clinical need, would build on existing federal-state programs, and would be affordable. On the basis of the experiences of state programs, if the new benefit covered 11.4 percent of the 32.8 million Medicare beneficiaries who are not eligible for Medicaid ${ }^{33}$ (the average participation rate for Connecticut, New Jersey, New York, and Pennsylvania) at an average cost per participant of $\$ 775$ (the cost in 1996), ${ }^{8}$ the annual costs of such a program would have been roughly $\$ 2.9$ billion in 1996, or about 3 percent of total Medicaid expenditures in that year. Assuming annual increases in drug costs of 12.6 percent ${ }^{8}$ the estimated cost of the program will be $\$ 4.1$ billion in 1999. ${ }^{14}$

A fully operational national program might resemble one of the successful state programs for pharmacy assistance, such as that in Pennsylvania or New Jersey (Table 1). Although drug coverage could be enacted as a new means-tested Medicare benefit, this might be less politically attractive than funding state programs, which could take advantage of existing Medicaid claims-processing and utilization-review systems. A precedent is the 1997 Children's Health Insurance Program, which allows states to expand existing Medicaid programs or to develop programs in local health care institutions.

Because poor Medicare enrollees have similar needs, regardless of where they live, standard eligibility criteria and benefits should be established. To maximize benefits, contain costs, and increase the program's acceptability to the federal government and the states, we recommend that the following principles be incorporated into the design of the program.

\section{Standardized Eligibility}

At a minimum, the program should cover Medicare enrollees with incomes below 200 percent of the federal poverty level (about $\$ 16,000$ for a single person) who are not eligible for Medicaid. This standard should be adjusted for differences among states in the cost of living. The data in Figure 2 suggest that drug use is markedly lower for persons with no drug coverage and annual incomes under $\$ 15,000$ than for those with higher incomes. States with pharmacyassistance programs have substantial experience in means testing to determine eligibility. In the three largest programs, the income threshold for eligibility ranges from $\$ 14,000$ to $\$ 18,500$ for a single person.

\section{Shared Financing}

Because the economic and clinical benefits of improved access to medication coverage accrue to both state and federal programs (e.g., reduced hospitalization rates in the Medicare program and reduced rates of nursing home admissions in the Medicaid program), both state and federal governments should share the costs of a national program, as they do with Medicaid. To ensure the participation of the states, we recommend the same "enhanced" federal-state spending rate as that in the Children's Health Insurance Program - that is, a 30 percent higher federal contribution than that for Medicaid programs.

\section{Progressive Cost Sharing}

Cost sharing is firmly established in most drugbenefit programs as a strategy for containing costs and discouraging unnecessary use. However, we believe that cost sharing should be progressive (i.e., based on a sliding scale), so that the poorest and sickest participants do not encounter barriers to use. For example, for persons with incomes below the federal poverty level we recommend no copayments or, at most, $\$ 1$ to $\$ 2$ per prescription; higher copayments would substantially reduce the use of essential medications in this population. ${ }^{13}$ Beneficiaries with incomes above this level could be charged higher copayments (e.g., \$5). Similarly, small deductibles should be considered only for the least poor enrollees. Because of the demonstrated risks of limits on drug benefits (such as limits on the number of prescriptions that can be filled each month) among the chronically ill, ${ }^{5,26}$ such limits should be avoided.

\section{Comprehensive Drug Formulary}

Because of constraints on resources, several state pharmacy-assistance programs limit coverage to drugs used to treat only a few chronic illnesses (Table 1) and exclude many effective classes of drugs for psychiatric and medical illnesses. Federal financing should encourage more comprehensive formularies.

\section{Vigorous Control Mechanisms}

To make sure that the state-level programs remain affordable and to encourage appropriate use of medications, the states should institute several of the measures used in existing Medicaid and drug-benefit programs: differential cost sharing to encourage the use of lower-cost generic drugs and agents that are clearly cost effective, rigorous utilization review, and educational programs mandated in Medicaid to improve the quality and efficiency of physicians' prescribing practices. ${ }^{39}$

This plan could be combined with other legislative initiatives. For example, if Congress ultimately mandates drug coverage for all Medicare enrollees, the proposed low-income program could supplement 
any such coverage provided under Medicare Part B (e.g., by offsetting high deductibles or copayments). But the first priority must be to provide immediate coverage for the most vulnerable low-income beneficiaries.

\section{SUMMARY}

In summary, most low-income elderly and disabled persons lack coverage for important medications, resulting in avoidable deterioration of health among those with chronic illnesses and use of expensive institutional services. Rapidly escalating drug costs, more restrictive drug-coverage policies, and a dramatic increase in the population of elderly and disabled persons will exacerbate these problems. With the current budget surplus, as well as bipartisan concern about health care needs and public concern about drug costs and coverage, ${ }^{20,40}$ it is time to act responsibly and aggressively. We recommend a national replication of the best features of state pharmacy-assistance programs in a federal-state insurance program for low-income Medicare enrollees, either alone or in combination with expanded Medicare coverage. Such a program will reduce the current inequitable situation in which the most vulnerable patients have the least access to medications, with serious medical and economic consequences.

\section{Stephen B. Soumeral, Sc.D. Dennis Ross-Degnan, Sc.D. \\ Harvard Medical School and Harvard Pilgrim Health Care Boston, MA 02115}

Supported in part by a grant (AG14474) from the National Institute on Aging, a grant from Danish International Development Assistance to the International Network for Rational Use of Drugs, and a grant from the Harvard Pilgrim Health Care Foundation.

We are indebted to Robert LeCates and Ann Payson for technical assistance, including tabulation of data; to David Gross, Ph.D., and Sharon Bee of the AARP Public Policy Institute for providing data on state pharmacy-assistance programs and drug coverage for Medicare beneficiaries; and to Cybele Bjorklund, Anne Montgomery, and Karen Lightfoot of the staffs of Senator Ted Kennedy, Representative Pete Stark, and Representative Henry Waxman, respectively, for information on current or proposed legislation.

\section{REFERENCES}

1. Rice T, Desmond K, Gabel J. Medicare Catastrophic Coverage Act: a post-mortem. Health Aff (Millwood) 1990;9(3):75-87.

2. Yankelovich D. The debate that wasn't: the public and the Clinton plan. Health Aff (Millwood) 1995;14(1):7-23.

3. Reinhardt UE. Turning our gaze from bread and circus games. Health Aff (Millwood) 1995;14(1):33-6

4. Lau J, Antman EM, Jimenez-Silva J, Kupelnick B, Mosteller F, Chalmers TC. Cumulative meta-analysis of therapeutic trials for myocardial infarction. N Engl J Med 1992;327:248-54.

5. Soumerai SB, McLaughlin TI, Ross-Degnan D Casteris CS, Bollini P. Effects of limiting Medicaid drug-reimbursement benefits on the use of psychotropic agents and acute mental health services by patients with schizophrenia. N Engl J Med 1994;331:650-5.

6. Health Care Financing Administration, Office of Strategic Planning. A profile of Medicare: chart book. Rockville, Md.: Department of Health and Human Services, 1998.

7. Laschober MA, Olin GL. Health and health care of the Medicare pop ulation: data from the 1992 Medicare Beneficiary Survey. Rockville, Md.: Westat, November 1996.

8. Levit K, Cowan C, Braden B, Stiller J, Sensenig A, Lazenby H. National health expenditures in 1997: more slow growth. Health Aff (Millwood) 1998;17(6):99-110.

9. Davis M, Poisal J, Chulis G, Zaraboso C, Cooper B. Prescription drug coverage, utilization, and spending among Medicare beneficiaries. Health Aff (Millwood) 1999;18(1):231-43.

10. Baugher E, Lamison-White L. Poverty in the United States: 1995.

Current population reports. Series P60-194. Washington, D.C.: Bureau of the Census, 1996:15.

11. Gross D, Caplan C, Gibson MJ. Estimates of financial burden of prescription drugs on beneficiaries in Medicare fee-for-service. Washington, D.C.: American Association of Retired Persons, September 1998.

12. Gross DJ, Alecxih L, Gibson MJ, Corea J, Caplan C, Brangan N. Outof-pocket health spending by poor and near-poor elderly Medicare beneficiaries. Health Serv Res (in press).

13. Soumerai SB, Ross-Degnan D, Fortess E, Abelson J. A critical analysis of studies of state drug reimbursement policies: research in need of discipline. Milbank Q 1993;71(2):217-52.

14. Pharmaceutical benefits under state medical assistance programs. Reston, Va.: National Pharmaceutical Council, November 1997.

15. University of Washington, Department of Pharmacy. Medicare man aged care: opportunities and concerns for pharmaceutical benefits. Pharmaceutical Outcomes Research \& Policy Program Report 1998;4(1):1-4. 16. Medex Gold enrollment halt sought. Boston Globe. November 10, 1998:Dl.

17. Current knowledge of third party outpatient drug coverage for Medicare beneficiaries. Fairfax, Va.: Lewin Group, November 9, 1998.

18. National health expenditures, 1996. Health Care Financ Rev 1996; 19(1):171-3

19. Lurie N, Ward NB, Shapiro MF, Brook RH. Termination from MediCal — does it affect health? N Engl J Med 1984;311:480-4.

20. The uncovered: drug costs can leave elderly a grim choice: pills or other needs. Wall Street Journal. November 17, 1998:1.

21. Fact sheet: 1999 Social Security changes. Baltimore: Social Security Administration, November 1998.

22. Testimony of Eva Berry, Joint Committee on Health and Human Resources, Legislature of the State of Maine. LD\# 2218, an act to implement the recommendations of the Task Force on Improving Access to Prescription Drugs for the Elderly, Augusta, Me., March 9, 1998.

23. Limits loom for seniors' drug benefits. Boston Globe. November 17, 1998:Al.

24. Soumerai SB, Avorn J, Ross-Degnan D, Gortmaker S. Payment restric tions for prescription drugs under Medicaid: effects of therapy, cost, and equity. N Engl J Med 1987;317:550-6.

25. Martin BC, McMillan JA. The impact of implementing a more restric tive prescription limit on Medicaid recipients: effects on cost, therapy, and out-of-pocket expenditures. Med Care 1996;34:686-701.

26. Soumerai SB, Ross-Degnan D, Avorn J, McLaughlin TJ, Chood

novskiy I. Effects of Medicaid drug-payment limits on admission to hospitals and nursing homes. N Engl J Med 1991;325:1072-7.

27. Rosenheck R, Cramer J, Xu W, et al. A comparison of clozapine and haloperidol in hospitalized patients with refractory schizophrenia. $\mathrm{N}$ Engl J Med 1997;337:809-15.

28. Gerdtham U-G, Hertzman P, Jonsson B, Boman G. Impact of inhaled corticosteroids on acute asthma hospitalization in Sweden 1978 to 1991. Med Care 1996;34:1188-98.

29. Donahue JG, Weiss ST, Livingston JM, Goetsch MA, Greineder DK, Platt R. Inhaled steroids and the risk of hospitalization for asthma. JAMA 1997;277:887-91.

30. Pedersen TR, Kjekshus J, Berg K, et al. Cholesterol lowering and the use of healthcare resources: results of the Scandinavian Simvastatin Survival Study. Circulation 1996;93:1796-802. [Erratum, Circulation 1996;94. 849.]

31. Fineberg HJ, Pearlman LA. Surgical treatment of peptic ulcer in the United States: trends before and after the introduction of cimetidine. Lancet 1981;1:1305-7.

32. Goldman L, Sia STB, Cook EF, Rutherford JD, Weinstein MC. Costs and effectiveness of routine therapy with long-term beta-adrenergic antag onists after acute myocardial infarction. N Engl J Med 1988;319:152-7.

33. Health Care Financing Administration, Office of Strategic Planning. A profile of Medicare: chart book. Rockville, Md.: Department of Health and Human Services, 1998:10.

34. Pharmaceutical benefits under state Medicaid assistance programs. Reston, Va.: National Pharmaceutical Council, 1997:2-33-2-36. 
35. Sheils JF Fishman A. Comprehensive Medicare reform: defined benefit vs. defined contribution. Fairfax, Va.: Lewin Group, 1998.

36. Drug companies slam Medicare-Discount Bill. Wall Street Journal. December 18, 1998:B1.

37. Drug prices: effects of opening federal supply schedule for pharmaceuticals are uncertain. Washington, D.C.: General Accounting Office, 1997 (GAO/HEHS-97-60.)

38. Medicaid: changes in best price for outpatient drugs purchased by
HMOs and hospitals. Washington, D.C.: General Accounting Office, 1994. (GAO/HEHS-94-194FS.)

39. Soumerai SB, Avorn J. Principles of educational outreach ('academic detailing') to improve clinical decision making. JAMA 1990;263:549-56. 40. Hard to swallow - America's soaring drug costs. Wall Street Journal. November 16, 1998:Al.

(C)1999, Massachusetts Medical Society. 


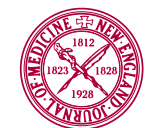

\section{INFORMATION FOR AUTHORS}

\author{
These guidelines are in accordance with the "Uniform Requirements for \\ Manuscripts Submitted to Biomedical Journals." (The complete document \\ appears in N Engl J Med 1997;336:309-15.)
}

MANUSCRIPTS Manuscripts containing original material are accepted for consideration if neither the article nor any part of its essential substance, tables, or figures has been or will be published or submitted elsewhere before appearing in the Journal. This restriction does not apply to abstracts or press reports published in connection with scientific meetings. Authors should submit to the Editor copies of any published papers or other manuscripts in preparation or submitted elsewhere that are related to the manuscript to be considered by the Journal. The Journal discourages the submission of more than one article dealing with related aspects of the same study.

Submit an original manuscript with one set of original figures and two copies of the complete manuscript. Manuscripts must be no longer than 3000 words. Please supply a word count (not including abstract or references). Use standard-sized paper, and triple-space throughout. Address all submissions to the Editor, New England Journal of Medicine, 10 Shattuck St., Boston, MA 02115-6094. A covering letter signed by all authors should identify the person (with the address and telephone number) responsible for negotiations concerning the manuscript; the letter should make it clear that the final manuscript has been seen and approved by all authors and that they have taken due care to ensure the integrity of the work. At least one person's name must accompany a group name - e.g., Thelma J. Smith, for the Boston Porphyria Group. As stated in the Uniform Requirements (see above), credit for authorship requires substantial contributions to: (a) conception and design, or analysis and interpretation of data; and (b) the drafting of the article or critical revision for important intellectual content. If more than 12 authors are listed for a multicenter trial, or more than 8 for a study from a single institution, each author must sign a statement attesting that he or she fulfills the authorship criteria of the Uniform Requirements. No more than 12 names will be listed under the title; other names will appear in a footnote. Acknowledgments will be limited to a column of Journal space, and those acknowledged will be listed only once. (See editorial, Nov. 21, 1991, issue.)

LETTERS TO THE EDITOR See the Journal correspondence section.

CONFLICT OF INTEREST Authors of research articles should disclose at the time of submission any financial arrangement they may have with a company whose product figures prominently in the submitted manuscript or with a company making a competing product. Such information will be held in confidence while the paper is under review and will not influence the editorial decision, but if the article is accepted for publication, the editors will usually discuss with the authors the manner in which such information is to be communicated to the reader.

Because the essence of reviews and editorials is selection and interpretation of the literature, the Journal expects that authors of such articles will not have any financial interest in a company (or its competitor) that makes a product discussed in the article.

COPYRIGHT Authors agree to execute copyright transfer forms as requested. Copyright in any contribution is owned by the Massachusetts Medical Society. The Society and its licensees have the right to use, reproduce, transmit, derivate, publish, and distribute the contribution, in the Journal or otherwise, in any form or medium. Authors will not use or authorize the use of the contribution without the Society's written consent, except as may be allowed by U.S. fair use law.

UNITS OF MEASUREMENT Authors should express all measurements in conventional units, with Système International (SI) units given in parentheses throughout the text. Figures and tables should use conventional units, with conversion factors given in legends or footnotes. In accordance with the Uniform Requirements, however, manuscripts containing only SI units will not be returned for that reason.

TITLES AND AUTHORS' NAMES With the manuscript, provide a page giving the title of the paper; titles should be concise and descrip- tive (not declarative). Also include a running head of fewer than 40 letter spaces; the name(s) of the author(s), including the first name(s) and no more than two graduate degrees; the name of the department and institution in which the work was done; the institutional affiliation of each author; and the name and address of the author to whom reprint requests should be addressed. Any grant support that requires acknowledgment should be mentioned on this page.

ABSTRACTS Provide on a separate page an abstract of not more than 250 words. This abstract should consist of four paragraphs, labeled Background, Methods, Results, and Conclusions. They should briefly describe, respectively, the problem being addressed in the study, how the study was performed, the salient results, and what the authors conclude from the results.

KEY WORDS Three to $10 \mathrm{key}$ words or short phrases should be added to the bottom of the abstract page; these will help us index the article and may be published with the Abstract. Use terms from the Medical Subject Headings from Index Medicus.

REFERENCES References must be triple-spaced and numbered consecutively as they are cited. References first cited in tables or figure legends must be numbered so that they will be in sequence with references cited in the text. The style of references is that of Index Medicus. List all authors when there are six or fewer; when there are seven or more, list the first three, then "et al." The following is a sample reference:

1. Lahita R, Kluger J, Drayer DE, Koffler D, Reidenberg MM. Antibodies to nuclear antigens in patients treated with procainamide or acetylprocain amide. N Engl J Med 1979;301:1382-5.

Numbered references to personal communications, unpublished data, and manuscripts either "in preparation" or "submitted for publication" are unacceptable (see "Permissions"). If essential, such material may be incorporated in the appropriate place in the text.

TABLES Double-space tables and provide a title for each. If an article is accepted, the Journal will arrange to deposit extensive tables of important data with the National Auxiliary Publications Service (NAPS); we will pay for the deposit and add an appropriate footnote to the text. This service makes available microfiche or photocopies of tables at moderate charges to those who request them.

ILLUSTRATIONS Figures should be professionally designed. Symbols, lettering, and numbering should be clear and large enough to remain legible after the figure has been reduced to fit the width of a single column.

The back of each figure should include the sequence number, the name of the author, and the proper orientation (e.g., "top"). Do not mount the figure on cardboard. Photomicrographs should be cropped to a width of $8 \mathrm{~cm}$, and electron photomicrographs should have internal scale markers.

If photographs of patients are used, either the subjects should not be identifiable or their pictures must be accompanied by written permission to use the figure. Permission forms are available from the Editor.

Legends for illustrations should be triple-spaced on a separate sheet and should not appear on the illustrations.

Color illustrations are encouraged. Send both transparencies and prints for this purpose.

ABBREVIATIONS Except for units of measurement, abbreviations are discouraged. Consult Scientific Style and Format: The CBE Manual for Authors, Editors, and Publishers (Sixth edition. New York: Cambridge University Press, 1994) for lists of standard abbreviations. The first time an abbreviation appears it should be preceded by the words for which it stands.

DRUG NAMES Generic names should generally be used. When proprietary brands are used in research, include the brand name in parentheses in the Methods section.

PERMISSIONS Materials taken from other sources must be accompanied by a written statement from both author and publisher giving permission to the Journal for reproduction.

Obtain permission in writing from at least one author of papers still in press, unpublished data, and personal communications.

REVIEW AND ACTION Manuscripts are examined by the editorial staff and are usually sent to outside reviewers. We encourage authors to suggest the names of possible reviewers, but we reserve the right of final selection. Only one copy of rejected manuscripts will be returned, usually within six weeks. Decisions about potentially acceptable manuscripts may take longer. 